\section{Another Alternative to Service Contracts}

Tony Nikischer, Excalibur Mineral Co. tony@excaliburmineral.com

In the October, 2001 issue of Microscopy Today, Randy Tindall described and compared his experiences with service contracts offered by insurance companies versus those offered by equipment manufacturers. As a small business with limited funds, we, too, grappled with the onerous costs of service contracts on our SEM and EDS units. However, we believe that we have found an extremely cost-effective means of protecting our equipment investment against the expense of a major failure.

First, a bit of business philosophy: We believe insurance should be designed to protect the insured from catastrophe, and not be expected to take care of every minor expense or inconvenience that may develop. If you disagree with this philosophy, or if you cannot endure an equipment outage of more than 24 hours under any circumstance you need not read any further. For our method to be effective, it is also imperative that sound operating procedures are followed, the equipment is wellmaintained (preferably using in-house capability), and users are well trained (and often).

That said, our secret, low cost approach to the service contract problem is simple: we do not purchase a service contract from anyone. Instead, we buy insurance known as "property floater coverage" for our high-tech, high-cost equipment as part of our overall insurance plan. If you are a business, university or research facility, you likely have such coverage already or can add it quite easily. It is most commonly used for such items as computer equipment or leased equipment in your possession.
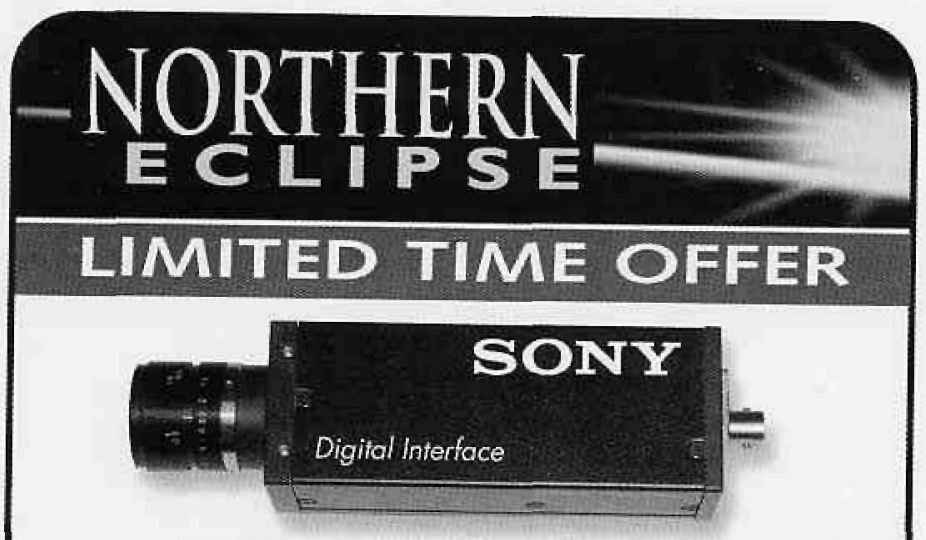

Sony Empix Digital Imaging System

Northern Eclipse or Northern Elite 6.0 PLUS Sony Digital Camera with Firewire ${ }^{\mathrm{TM}}$

Get the most powerful imaging software and a high quality Sony Digital CCD camera for one low price. Includes 3 levels of automation, De-convolution, 3-D Reconstruction, Adaptive Threshold, AVI support, and hundreds of other processing and analysis functions, plus a Sony Digital Mega Pixel Camera. Sony XCD X700 camera, Northern Elite software, card and cable for only $\$ 3695.00$ U.S. Contact Empix Imaging Inc. at:

www.empix.com

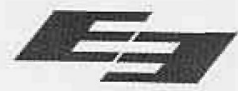

EMPIX

TM 'Firewire' is a registered trademark of Apple Computer Inc.
This form of insurance can be used to guard against catastrophic damage or loss, and we specifically request "equipment failure coverage" in addition to other potential losses that could befall such equipment. Note that typical insurance company exclusions apply: earthquakes, volcanic eruptions, war, mud slides, etc..

So, what happens when the detector window on the EDS unit ruptures? Or a local utility problem suddenly takes out a transformer bank, spiking the SEM's circuitry and blowing out several power modules? Here's what you can expect:

1) Call the equipment manufacturer (or other service provider) and request an emergency repair visit. (Yes, you may have to wait as Randy Tindall properly pointed out, since the OEM provider has first obligation to service contract holders.) In our experience, if there is a good working relationship with the OEM's team, the call will be handled as expeditiously as they can manage. They still want your repair business, service contract or not!

2) Expect that they will ask for a Purchase Order, so have one ready to fax.

3) Call the insurance company and let them know about the outage and the circumstances that led to it (if known). Ultimately, they may want to talk to the OEM, and they will want copies of all invoices received.

4) The service provider will send an invoice once everything is up and running, and they typically give 30 days to pay it. Do so.

5) Provide all invoices to the insurance carrier as the final part of the claim. Depending on the company, 30 to 60 days later, the claim check will be on its way, assuming the claim is valid (see exclusion list) and not the result of negligence or fraud. Payment will typically cover the entire repair bill, less the deductible.

The cost of this protection is minimal. In our experience, each rider has cost us less than $10 \%$ of an annual service contract. By having a moderate deductible (say, $\$ 1000$ ), we further reduce this cost. In the past six years, we have had two catastrophic failures. Both were fully covered and only cost us our deductible. Compared to the cost of six years of service contracts, we saved a significant sum in exchange for modest inconvenience in downtime.

Caveats: If you have an unacceptable failure rate in your lab already, you may not be maintaining the equipment or instructing your staff properly. The insurance carrier won't tolerate constant failures (and neither should you!), and this process will quickly breakdown as the carrier summarily dumps you or raises your premium. If the equipment repair history is poor, stay with the OEM and figure out why. If, on the other hand, you meet the proper user profile, talk to your insurance people about this approach. It can save you a significant portion of the annual maintenance budget.

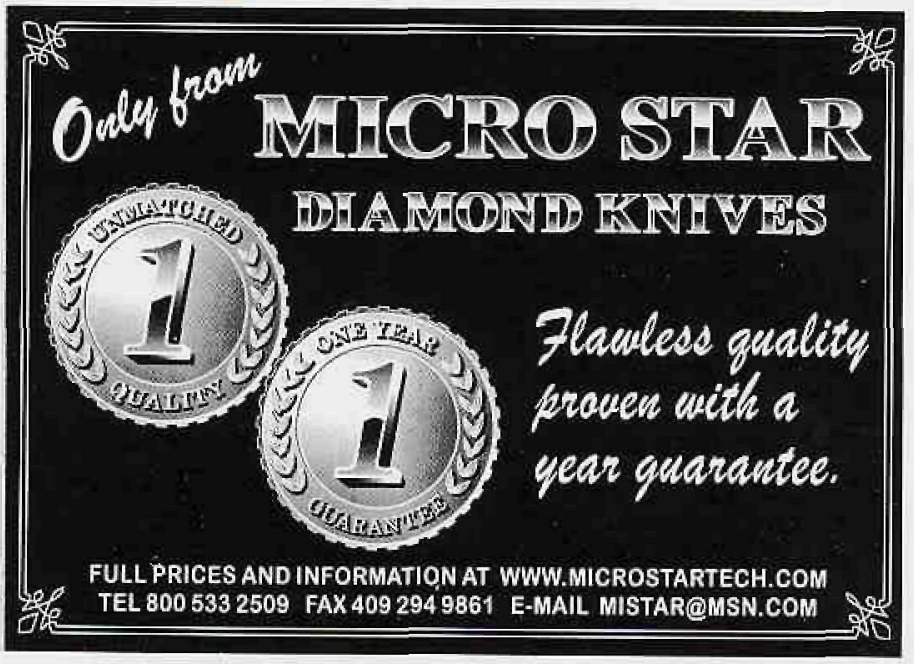




\section{Biological Microscopy Facility Core Manager}

NEW YORK MICROSCOPICAL SOCIETY 2002 WORKSHOPS

$\checkmark$ April 20\& 27, May 4 \& 11: Polarized Light Microscopy

$\checkmark$ May 3: Digital Image Capture \& Management in Light Microscopy Montclair, NJ, Donald O'Leary: (201)797-8849, donoleary@att.net

YEAR 2002 APPLIED OPTICAL MICROSCOPY CALENDAR

Smithsonian Ctr for Materials Research \& Educ. (Suitland, MD)

$\checkmark$ March 11/15: Microscopy of Protective and Decorative Coatings

$\checkmark$ April 8/12: Practical Wood Anatomy in a Museum Environment

$\checkmark$ July 8/12: Polarized Light Microscopy - kFundamentals and Applications

For further information: Ms. Francine Lewis: (301)238-3700 X102

YEAR 2002 MARINE BIOLOGICAL LAB, Woods Hole, MA. Carol Hamel, (508)289-7401, admissions@mbl.edu

$\checkmark$ May 9/17 02 : Analytical \& Quantitative Light Microscopy

$\checkmark$ May 21/28 02: Microinjection Techniques in Cell Blology

$\checkmark$ Oct 10/19 '02: Optical Microscopy \& Imaging in the Biomedicl Sciences

$\checkmark$ March 17/22 '02: PITTCON 2002 New Orleans, LA. (412)8253220, program@pittcon.org

$\checkmark$ April 8/10 '02: NIST-MAS Special Topics Workshop, Understanding the Accuracy Barrier in Quantitative Electron Probe Microanalysis and the Role of Standards. (NIST), Gaithersburg, MD. (301)417-1321, www.ni st.gov

$\checkmark$ May 5/8 02: Food Structure \& Functionality Symposium Montreal Quebec, www.aocs.org/member/division/fsff/index.htm

$\checkmark$ May 22/June 1: EMBO Practical Course on Electron Microscopy, Immunocytoche mistry and Stereology for Cell Biology (EMBL) Heidelberg, Germany. www.db.embl -heidelberg. de/CoursesConferecnes.html

$\checkmark$ June 5/12 02: Optical Microscopy in the Biological Sciences (Univ. of Texas Health Science Ctr), San Antonio, TX, Victoria Centonze Frohlich, frohlich@uthscsa.edu, www.uthscsa.edu/csb/image/Announcements.html

$\checkmark$ June 10/20: 3D Microscopy of Living Cells (\& June 22/24: Postcourse Workshop) Vancouver, BC, Canada. www.3dcourse.ubc. ca/home.html

\section{LEHIGH MICROSCOPY SCHOOL}

$\checkmark$ June 10/14: SEM and X-ray Microanalysis

$\checkmark$ June 9: Introduction to SEM and EDS

$\checkmark$ June 17/20: Advanced Scanning Electron Microscopy

$\checkmark$ June 17/20: Quantitative X-ray Microanalysis

$\checkmark$ June 17/20: Analytical Transmission Electron Microscopy

$\checkmark$ June 18/21: EM Specimen Preparation

$\checkmark$ June 18/21: Atomic Force Microscopy

$\checkmark$ June 17/20: Characterization of Nanostructures

Lehigh Universtiy, Bethlehem, PA

For info: Sharon Coe, (610)758-5133, sharon.coe@lehigh.edu

$\checkmark$ June $16 / 21$ '02: Fourth Annual Course in Quantitative Fluorescence Microscopy Arcadia National Park, Maine. Simon Watkins: (412)648-3051, swatkins+@pitt.edu

$\checkmark$ June 24/27 '02: 17th Annual Short Course on Molecular Microspectroscopy (Miami Univ.) Oxford, $\mathrm{OH}$ (513)529-2874, Www. muohio.edu/mml

$\checkmark$ July 9/11 '02: MICROSCIENCE London, UK, Info@rms.org.uk, www.rms.org.uk/microscience2002

$\checkmark$ August 4/9 02 : Microscopy \& Microanalysis 2002 (MSA/MAS) Quebec City, Canada. http://msc.rsvs.ulaval.ca

$\checkmark$ August 12/16 '02: UltraPath Xi (Society' for Ultrastructural Pathology) Aspen, Co, Gary Mierau: (303)861-6170,
Cold Spring Harbor Laboratory is seeking an experienced and responsible Biological Microscopy Facility Core Manager for the laboratory's state-of-the-art central microscopy facility. The individual should have practical expertise in transmission electron microscopy, confocal and widefield fluorescence microscopy, and digital imaging. The successful candidate will be involved in designing and carrying out experimental protocols for users, training individuals in the use of various microscopes, aligning microscopes and keeping the facility operating at an efficient and high level of productivity.

We offer a competitive salary including comprehensive benefits plus childcare. For immediate consideration, interested individuals should send their resume, including a description of their expertise and the names and addresses of 3 references to: Dr. David L. Spector, Cold Spring Harbor Laboratory, One Bungtown Road, Cold Spring Harbor, New York 11724, email: spector@cshl.org

\section{Equal Opportunity Employer}

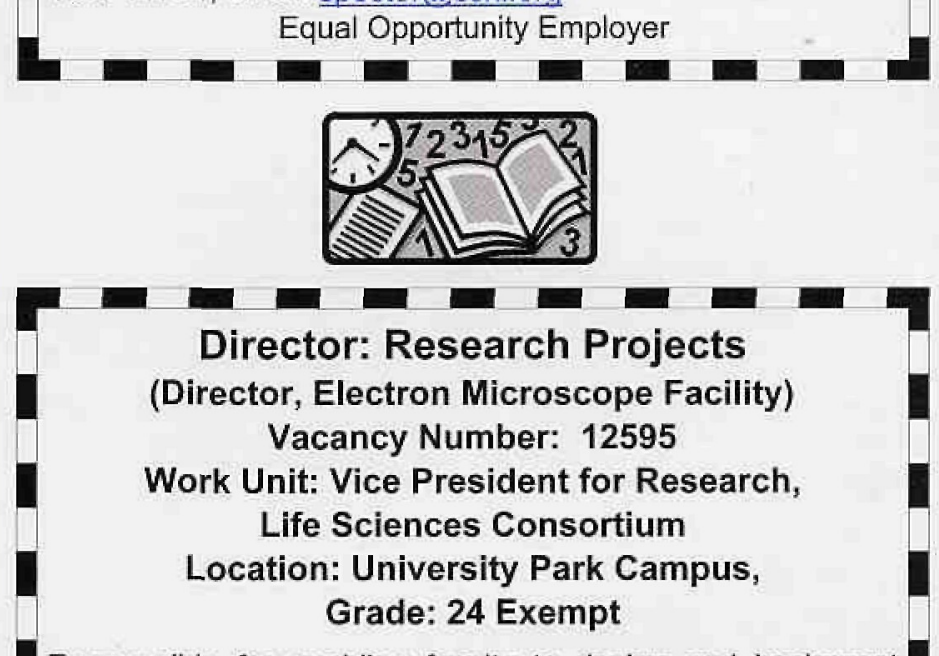

Responsible for enabling faculty to design and implement protocols using transmission and scanning electron microscopes, as well as image and analyze biological and material samples. Responsible for the maintenance and operation of light microscopes, digital camera interfaces for light and EM microscopy, computers and sample preparation equipment. Train EM personnel and researchers in sample preparation techniques and the efficient operation of instrumentation; teach laboratory courses; develop fee structure; and participate in the development of instrumentation grant proposals.

Requires a Master's degree (Ph.D. preferred) or equivalent in Biology, Biochemistry, Molecular Biology or related field, plus two years of previous experience in electron microscopy and two years of a research program. Computer and interpersonal skills required.

Pennsylvania State University is committed to affirmative action, equal opportunity and the diversity of the workforce. Please email or FAX resume and cover letter to:

\section{Judith Burns, Mgr. STF SVCS, jeb2@psu.edu \\ The Life Sciences Consortium 519 Wartik Lab \\ University Park, PA 16802}

